\title{
FAMÍLIAS OPERÁRIAS MINEIRAS E RELAÇÕES DE GÊNERO: a construção do feminino através de cursos populares na região carbonífera catarinense (1950-1960)
}

\author{
Ismael Gonçalves Alves*
}

\section{Resumo}

No auge de sua atividade mineradora, o município de Criciúma atraiu para suas minas de carvão milhares de pessoas que se deslocaram do litoral sul de Santa Catarina em busca de emprego na cidade. Sem experiências concretas com o mundo urbano e do trabalho, regulado pelo tempo e pela produtividade, estes novos habitantes foram apontados pelos empresários e pelas elites locais como responsáveis pela baixa produtividade do setor e pelos problemas médico-sanitários que afetavam cotidianamente a cidade. A fim de reverter esta situação, a Carbonífera Próspera S.A., o SESI-SC e a ordem religiosa das Pequenas Irmãs da Divina Providência, iniciaram um amplo processo de remodelação de suas práticas cotidianas, do qual a família, centrada na figura da mulher (esposa e mãe), foi o alvo principal. O modelo de feminilidade adotado pela ordem religiosa, hegemônico em boa parte da ocidentalidade, era aquele em que a mulher só encontraria realização e felicidade plena dentro do ambiente doméstico. Para dar conta de tal empreitada, foi desenvolvida uma série de cursos populares direcionados ao espaço doméstico, reforçando a imagem da mulher como esposa, dona-de-casa e mãe-defamília.

Palavras-Chave: Relações de Gênero. Família. Biopolítica.

\section{Introdução}

Durante as primeiras décadas do século 20, operou-se, no complexo carbonífero sulcatarinense, um rápido processo de crescimento econômico, urbano e populacional, conduzido por inúmeras mineradoras de médio e grande porte, que atraíram para o interior de suas minas de carvão um elevado contingente de trabalhadores. Sem experiência concreta com o mundo citadino e seus códigos de civilidade, estas novas populações foram apontadas

\footnotetext{
* Doutorando pelo Programa de Pós-Graduação em História da Universidade Federal do Paraná. E-mail: ismaelmaya1@yahoo.com.br
} 
pelas elites locais como responsáveis pela baixa produtividade do setor, pelos "problemas" médico-sanitários que passavam à massa de trabalhadores da cidade. Baseadas no discurso sanitarista, diversas ações sociais foram empreendidas por autoridades municipais, entidades assistenciais e governo federal a fim de promover um amplo plano de assistência social capaz de abranger desde a construção de novas moradias até a expansão dos serviços médicohospitalares.

Esta interação entre diferentes estruturas sociais e os agentes governamentais foi analisada pela historiadora norueguesa Anne-Lise Seip (apud MARTINS, 2004, [a] p.24), em suas pesquisas sobre a formulação de políticas públicas no contexto europeu, no qual o entrelaçamento do Estado com diversos setores da sociedade foi de fundamental importância na implementação de políticas de bem-estar para a população mais pobre. Este mix entre público e privado foi chamado pela historiadora de triângulo welfare state. A triangulação oferecida por Anne-Lise Seip, além de desvelar diversos aspectos da miríade relacional existente entre as diversas instâncias do poder, permite perceber as conotações de gênero existentes no interior das estruturas executivas de políticas públicas, pois, ao privilegiar as relações sociais, ela destaca o enfrentamento estabelecido entre homens e mulheres, mulheres e mulheres, homens e homens, na promoção de políticas públicas de amparo às mulheres e às crianças pobres.

Nos países europeus, como Dinamarca, Noruega, Suécia, ou nos Estados Unidos, as políticas assistenciais elaboradas pelos governos centrais percebem as mulheres como indivíduos com necessidades de fundamental importância nas relações sociais, concedendolhes benefícios para diminuir a pobreza que cerca o seu cotidiano - a exemplo das políticas de maternidade (LARSEN, 1996). Diferentemente da Europa e da América do Norte, o Estado brasileiro é essencialmente paternalista, concedendo assistência às classes trabalhadoras e suas famílias. Nas engrenagens burocráticas que movimentavam a máquina pública brasileira, as mulheres são percebidas como um apêndice do homem provedor, sendo atendidas apenas na eventualidade de vínculos conjugais e família numerosa, ficando excluídas desta modalidade assistencial as mães solteiras, trabalhadoras rurais e domésticas. Neste sentido, a mulher é vista como instrumental, pois, para se chegar à família e às crianças, finalidades de governo, é necessário articular um conjunto de ações assistenciais que protejam a mulher/mãe, cercando-a de cuidados e benefícios, a fim de resguardar, através disto, a família e a infância. 


\begin{abstract}
Nesse contexto, os grupos populares urbanos tinham um papel fundamental, pois constituíam a chamada classe trabalhadora, responsável pelo labor na indústria, no comércio e nos serviços. Para os "trabalhadores do Brasil" foram instituídas pelas autoridades federais políticas sociais nas áreas do direito trabalhista, da previdência social, da saúde pública, da assistência social e da economia. Essas políticas sociais de caráter nacional somavam-se a outras levadas a cabo pelas autoridades varguistas em âmbito regional e municipal (AREND, 2007, p. 100-101).
\end{abstract}

Neste artigo, buscarei ater minhas análises às relações estabelecidas entre a Companhia Mineradora Próspera S/A., o Serviço Social da Indústria (SESI-SC) e as Pequenas Irmãs da Divina Providência que, através de um conjunto de cursos populares, tentaram transformar as mulheres da vila operária em uma peça central do processo de aculturação das famílias trabalhadoras. Segundo Jurandir Freire Costa (1989, p. 35), a higienização da família popular brasileira acompanhou diretamente o desenvolvimento urbano das cidades industriais, pois, ao se envolverem no fenômeno da modernização, estes novos centros urbanos exigiam de seus habitantes um cortejo de mudanças relacionadas às antigas práticas cotidianas consideradas insalubres e anti-higiênicas.

Para o desenvolvimento destas analises, utilizei algumas fontes documentais encontradas nos acervos locais. Dentre elas, destaca-se o Álbum/relatório das Pequenas Irmãs da Divina Providência destinado ao SESI-SC, que traz um detalhado e ilustrado balanço de todas as atividades realizadas pelas religiosas no período de 1955 a 1957. Ricamente ilustrado por fotos, contendo um minucioso relato de suas experiências junto aos habitantes da Vila Operária Próspera, constituiu um precioso elemento analítico que visou a compreender o multifacetado cotidiano das irmãs e as relações sociais estabelecidas entre elas e os residentes locais.

Além das fontes escritas, utilizei também algumas das entrevistas que realizei ao longo dos anos de 2007 e 2008, com os antigos moradores na vila operária Próspera. ${ }^{1}$ Esta empreitada com as memórias dos antigos habitantes da vila teve o objetivo de identificar como as ações normatizadoras, empreendidas pelas religiosas, a pedido do SESI-SC e da Carbonífera, foram ressignificadas pelos moradores deste local de habitação.

O trabalho aqui apresentado buscará, desta forma, seguir algumas perspectivas teóricometodológicas que permearão toda a discussão em torno da problemática, buscando, assim, construir um escopo analítico que tratará da vida ordinária das mulheres que de alguma forma tiveram seu cotidiano envolvido pelas atividades mineradoras. Segundo Michel Pollack (1989, p. 4), ao centrar-se na análise dos excluídos, dos marginalizados, das mulheres e das

\footnotetext{
${ }^{1}$ Os nomes dos entrevistados foram modificados a fim de preservar suas identidades.
} 
minorias, a história oral realça o valor das memórias subterrâneas, que, como parte das culturas minoritárias e dominadas, se opõem à memória oficial. O trabalho com as reminiscências revela toda a complexidade da vida cotidiana, na qual as lembranças trazem consigo parte de experiências individuais, saturadas de sentimentos e cicatrizes. Para David Lowenthal (1998, p. 75), “toda consciência do passado está fundada na memória. Através das lembranças recuperamos consciência de acontecimentos anteriores, distinguimos o ontem do hoje, e confirmamos que já vivemos um passado".

Ao enveredar pelos meandros da vida pessoal, o/a historiador/a é levado/a a percorrer sinuosos caminhos analíticos que muitas vezes o/a conduzem a lugares ermos; todavia, esta aventura também pode abrir uma infinidade de possibilidades para a compreensão da vida coletiva, que os registros oficiais fizeram questão de esquecer. Segundo Paul Thompson (1992, p. 20), a História não pode ser entendida como algo factual, isolado, sem conexão com o presente, “evitando qualquer envolvimento com interpretações mais amplas de questões contemporâneas, insistindo apenas na busca do conhecimento pelo conhecimento”. Para o autor, a História deve ser um caminho para compreender mudanças, rupturas e continuidades, dando visibilidade a sujeitos que durante muito tempo foram fadados ao esquecimento ou à marginalidade da pesquisa.

Ao ressaltar a importância do trabalho com as minorias, as historiadoras Rachel Soihet e Joana Maria Pedro (2007, p. 282-284) destacam a importância da "História das Mulheres e das Relações de Gênero” no campo historiográfico, ao questionar o motivo dos silêncios que as envolviam como sujeitos históricos. De acordo com as autoras, estas novas categorias de análise contribuíram para a quebra do paradigma do sujeito universal, representado pela categoria "homem", com o qual se convencionou, durante muito tempo, que ao se falar nele se estariam contemplando também as mulheres. Na trilha aberta pela história das mulheres, pesquisadoras e pesquisadores têm buscado, com maior frequência, dedicar seus estudos à vida ordinária das mulheres, a suas lutas, resistências, trabalhos e sobrevivências, procurando destacar a importância destas análises para o entendimento das relações de poder que permeiam a nossa sociedade, baseada fortemente em valores sexistas (PEDRO, 2005, p. 85).

Ainda segundo a historiadora Joana Maria Pedro, foi com a “História das Mulheres” que surgiu a categoria "gênero", com a finalidade de dar conta da diferença dentro da diferença (PEDRO, 1994). Priorizar as relações de gênero dentro da pesquisa histórica é procurar dar visibilidade, sobretudo, mas não somente, à atuação de mulheres e de outras minorias de gênero, que durante muito tempo ficaram à margem da produção de conhecimento. A aproximação com este tipo de estudos contribuiu sistematicamente para o 
fornecimento de novas ferramentas teóricas e metodológicas para a interpretação da realidade, possibilitando re-significações e re-elaborações de questões centrais para as ciências humanas. Neste sentido, "gênero [...] é um conceito usado por aqueles que entendam não apenas a desigualdade sexual, mas muitas das diferenciações sexuais, como socialmente construídas” (OKIN, 2008, p. 306).

É através destas relações de poder, que se capilarizaram no interior das estruturas sociais, que buscarei compreender como se articulou um conjunto de ações que buscaram construir modelos idealizados de feminino nas vilas operárias no sul de Santa Catarina. Ações sociais que utilizaram um conjunto de cursos populares, cujo objetivo era claramente o de alinhar as identidades de gênero a um modelo totalizante e socialmente aceito, no qual as mulheres eram as responsáveis pela administração da casa e da família.

\section{Construindo uma nova mulher: a redefinição do feminino na vila operária}

O projeto político-social de remodelação das condutas que se operou paulatinamente sobre as camadas mais pobres da região carbonífera tinha por finalidade apagar as imagens de ignorância, rudeza e superstição que, durante muito tempo, foram associadas à figura dos trabalhadores urbanos no Brasil. Integrá-los à cidade, incutindo hábitos moralizados, em oposição às antigas práticas consideradas promíscuas e insalubres, implicou remodelar suas práticas sociais com a introdução de um novo valor: “os indivíduos deveriam adquirir a convicção da importância que o Estado tinha na preservação da saúde, bem-estar e progresso da população" (COSTA, 1989, p. 56).

A promoção destas novas relações sociais alicerçou-se sobre dois pilares: o primeiro, diz respeito à ressignificação das moradias. A nova casa tinha de ser capaz de atender às crescentes demandas provenientes das classes trabalhadoras, como água encanada, eletricidade e rede de esgoto. Organizada e detentora de espaços privatizados, instituiria o gosto pela intimidade, trazendo para dentro do lar o marido e os filhos. O segundo ponto trata da reordenação das práticas desempenhadas por cada membro da família no interior do espaço doméstico, ou seja, esta remodelação de condutas implicaria instituir sobre o grupo familiar valores ligados à moral burguesa segundo a qual o homem era o provedor, a mulher a rainha do lar e as crianças, o bem maior do casal.

Fazer com que a mulher regressasse para o interior do espaço doméstico, cumprindo com aquelas que seriam suas funções naturais, foi o principal mote de atuação da empresa 
mineradora Próspera S/A. e do SESI-SC, na tentativa de impor às famílias operárias da região novas práticas e valores . De acordo com as historiadoras Marina Maluf e Maria Lúcia Mott (1999, p. 374), nos anos 1950 “o lugar da mulher é o lar, e sua função consiste em casar, gerar filhos para pátria e plasmar o caráter dos cidadãos de amanhã”. Este novo modelo de feminilidade, marcado pela intimidade e pela valorização da maternidade, tinha por objetivo transformar a mulher na baliza moral da casa, com a função específica de tornar seus familiares entes civilizados e compatíveis com as demandas do mundo moderno, em suma, implementar “[...] novas alternativas de convivência social, [de] reorganização das vivências familiares e domésticas, [...] que responderiam pela instauração de um novo modelo de vida, o estilo burguês” (MUNIZ. In: COSTA; MACHADO (orgs); 2000, p. 130).

Segundo a antropóloga social Cláudia Fonseca (1996, p. 516-517), o discurso da norma familiar burguesa, fundamentado na idéia de que não existiria realização feminina fora da esfera doméstica, não chegou a todas as camadas da população da mesma maneira. A mulher pobre sobrevivia apenas dos parcos recursos conseguidos por seu marido no trabalho industrial, ou em bicos realizados nas redondezas de sua moradia, o que não era suficiente para suprir as necessidades da família. Esta situação de quase miséria impulsionava boa parte das donas-de-casa pobres ao mundo do trabalho, na tentativa de escapar da pobreza, mesmo correndo o risco de serem rotuladas de “mulheres públicas”. Ao invés de serem admiradas como os homens, por serem trabalhadoras, elas precisavam constantemente defender sua reputação como boas donas-de-casa, esposas e mães, pois, ao escapar da esfera do privado, inscrevia-se nelas o estigma da culpa, do abandono do lar, dos filhos carentes e do marido exausto em função das longas jornadas de trabalho.

No Brasil, as amarras que proibiam o trabalho feminino afrouxaram-se no contexto das duas grandes Guerras, sobretudo no período que compreendeu a Segunda Guerra Mundial. A escassez de mercadorias, a grande procura por produtos industrializados e materiais bélicos e o envio dos homens para o front de batalha impulsionaram as mulheres para o interior do mercado de trabalho, onde passaram a desempenhar diferentes profissões. Neste período, parte das mulheres que habitavam as áreas de mineração em Criciúma também foi contratada para trabalhar no processo de produção do carvão. Este movimento, mesmo que de maneira tímida, alinhava-se aos discursos estrangeiros que fomentavam a maior participação feminina no mercado de trabalho, com o intuito de normalizar o processo industrial. Nas minas da cidade, as mulheres ocuparam o cargo de escolhedeiras, trabalhando em grandes galpões instalados nos pátios das minas, cabendo-lhes separar o carvão mineral bruto do seu rejeito, a pirita (CAROLA, 1997). 
Com o término da Guerra, as mulheres foram novamente impelidas a retomar sua antiga posição de donas-de-casa, sendo alvo de uma intensa propaganda produzida pelo Estado, por instituições filantrópicas e pela Igreja Católica Apostólica Romana, que pregavam seu retorno ao lar. Na vila operária Próspera, com o término da Segunda Guerra, assim como em outras partes do País, também cessaram as oportunidades de emprego para as mulheres no ambiente produtivo da indústria. Segundo a historiadora Carla Bassenezi:

Se o Brasil acompanhou, à sua maneira, as tendências internacionais de modernização e de emancipação feminina - impulsionadas com a participação das mulheres nos esforços de guerra e reforçadas pelo desenvolvimento econômico -, também foi influenciado pelas campanhas estrangeiras que, com o fim da guerra, passaram a pregar a volta das mulheres ao lar e aos valores tradicionais da sociedade (1996, p. 608).

Apesar da intensa difusão do discurso sobre a família nuclear burguesa, este não foi apreendido da mesma forma nas diferentes camadas da população brasileira, como já afirmado anteriormente. Segundo a socióloga Martine Segalen (1999, p. 13), dentre as camadas urbanas pobres, este discurso teve maior ressonância entre aqueles que de alguma forma estavam atrelados à indústria pesada do aço e do carvão. Para a autora, "quando predomina a indústria metalúrgica e mineira, que emprega essencialmente a mão-de-obra masculina, as famílias são geralmente nucleares, ficando a mulher em casa”, cuidando do marido e dos filhos.

Dessa maneira, desenhavam-se os contornos de uma nova mulher, que deveria ser, acima de tudo, afetuosa e dedicada à sua família, fazendo cumprir um projeto social que se acoplava ao seu destino biológico de ser mãe, que teria como recompensa o filho saudável (MATOS; MORAIS, 2007, p. 27).

Na década de 1950, as Pequenas Irmãs da Divina Providência, em conjunto com o SESI-SC, passaram a ofertar na vila operária Próspera uma série de cursos populares voltados à economia doméstica e à arte de bem gerir as atividades ligadas ao lar, fortemente marcados pelas “[...] ideologias veiculadas pelo positivismo e pelo higienismo [que] encarregaram-se de manter a mulher no espaço doméstico e a impor regras de conduta que regulavam seu comportamento em limites estreitos” (ALMEIDA, 2007, p.109). Ao confinar a mulher no espaço do doméstico, a sociedade burguesa condicionou a felicidade feminina à satisfação dos anseios familiares, entre os quais os cuidados com o marido e os filhos, para elas as principais prioridades. Em nome da preservação da família, manteve-se, durante muito tempo, o "nível baixo da educação feminina, fornecendo à mulher apenas a formação necessária à educação 
dos filhos” (XAVIER, 1998, p. 23). Neste sentido, seguindo as recomendações do médico Francisco de Paula Boa Nova Junior² ${ }^{2}$ que há tempos alertava para a deficiência alimentar entre os trabalhadores do carvão e seus filhos/as, o primeiro curso oferecido pelas religiosas foi o de arte culinária. Para o sanitarista, uma boa alimentação seria capaz de diminuir as agitações existentes no meio operário e atenuar os efeitos negativos sobre a sua produtividade.

A fome apresenta-se na região carbonífera sul catarinense, como aliás nos demais meios operários, sob o duplo aspecto de alimentação e má alimentação. Algumas vezes são as dificuldades da vida (salários baixos e preços exorbitantes) que obrigam o operário e à sua família à alimentação parca, insuficiente; outras vezes, porém, o mal consiste em que o operário podendo bem alimentar-se, come maior quantidade mas com pouco proveito, porque come o que não deve e não come o que necessita. [...] A boa alimentação, não só do operário como de sua família, é um complemento indispensável do bem estar social, pois, se o problema alimentar fosse apenas resolvido para o operário, este não poderia, logicamente, sentir-se satisfeito e tranqüilo vendo que tal problema continuava a existir para a mulher e os filhos. Portanto, não se poderá deixar de sempre pensar, também, na alimentação da família do operário (BOA NOVA JUNIOR, 1953, p. 101).

Para as religiosas das Pequenas Irmãs da Divina Providência e o SESI-SC, o curso de arte culinária teria um duplo efeito. Ao tempo em que proporcionaria uma alimentação saudável ao operário, reforçava a representação social da mulher enquanto responsável pelo bem-estar da família. Esta educação, voltada para o doméstico, fazia “dela um anjo de bondade, redentora da família e da pátria”, e somente por sua obra meritória [o país] "firmarse-ia entre as grandes nações do mundo" (ALMEIDA, 2007, p. 109). De acordo com as informações presentes no álbum-relatório das freiras, a má alimentação da população operária não era o único resultado da falta de recursos financeiros, mas também da má vontade e preguiça das esposas e mães ou, ainda, decorrência da falta de habilidade das mulheres para cozinhar. Eis os argumentos apresentados pelas freiras para a instituição do curso de arte culinária:

É conhecida (sic.) a base de alimentação da grande maioria dos habitantes da Próspera: pirão d’água, ou melhor, farinha de mandioca e água, misturados à hora de servir com peixe cozido. É este o prato que constitui a alimentação dos pobres operários que trabalham em serviço tão exaustivo de duro. Sabemos que a pobreza não justifica isto, e sim o descuido, a lei do menor esforço. No intuito de corrigir em parte este lamentável erro, começamos a

\footnotetext{
${ }^{2}$ Médico-sanitarista contratado pelo Departamento Nacional de Produção Mineral, para fazer os levantamentos sobre a baixa produtividade do setor carbonífero catarinense.
} 
estudar a possibilidade de um pequeno Curso de Arte Culinária (ÁLBUM/Relatório, 1955-1957).

A primeira demonstração do curso foi realizada dia 16 de maio de 1957, com o Grupo das Floristas, que agregava filhas dos mineiros que moravam na vila operária Próspera. Esta iniciativa, de principiar o curso com as mulheres mais jovens, tinha a intenção de incentivar desde cedo o gosto pelas atividades domésticas e, ainda, fomentar entre suas mães e vizinhas as benesses do cuidado com a alimentação e da boa cozinha. Iniciadas desde pequenas nas atividades laborais ligadas à vida ordinária da família, “[...] o trabalho doméstico [...] vai condicionando-as no sentido de renunciarem a si mesmas [fazendo-as] reconhecerem-se como as mais "zelosas da casa”, mais cuidadosas e mais ajeitadas [...]," verdadeiras "herdeiras" do espaço doméstico, "reino perpétuo" das mulheres na Terra (MADEIRA, 1997, p. 372). Eis o comentário contido no relatório sobre o referido curso:

Com o grupo das floristas fizemos uma pequena experiência realizando um almoço e o resultado foi magnífico. [...] Chegando em casa contaram para as mães e vizinhas, tudo que haviam feito e aprendido em um só almoço e isto valeu, como eficaz propaganda. Aproveitamos o calor do entusiasmo para uma reunião com as senhoras, convidando-as para o pequeno Curso de Culinária que pretendíamos iniciar (ÁLBUM/Relatório, 1955-1957).

Durante o curso, cada dona-de-casa ficava responsável por levar uma porção de alimento. Dessa forma, dividiam-se as despesas para a manutenção das aulas e ainda se incentivava o espírito de solidariedade entre as “donas-de-casa”. Separadas em grupos, cada uma ficava responsável pelo preparo de um determinado tipo de alimento (verduras, carnes, grãos, etc.), que depois seria apresentado em belos pratos decorados. Todavia, dominar a arte da culinária não era somente saber cozinhar e preparar os alimentos. Ao longo do curso, as donas-de-casa ainda aprendiam a desinfetar os alimentos e também os utensílios domésticos. De acordo com Máximo da Silva, durante o século 20 o espaço da cozinha e seus apetrechos ganham novos significados, diretamente influenciados pelo aparato médico-estatal, no qual se seguiam rigorosamente as normas de higiene recomendadas pelos sanitaristas, que exerciam forte controle sobre o espaço doméstico.

A presença da cozinha modificada no espaço da casa trouxe transformações na execução das tarefas, principalmente no preparo dos alimentos, considerado essencial para a boa saúde da família. A cozinha, um espaço altamente desprestigiado, passou a ser o alvo principal das autoridades educadas pelo saber médico, que a considerava um espaço essencial, que 
precisava ser agregado ao corpo principal do lar e as lógicas impostas pelos ideais de urbanização e consumo (SILVA, 2008, p. 144).

Profundamente pressionado pelos ditames sanitaristas, o trabalho doméstico relativo ao espaço da cozinha passou a ser submetido a uma nova lógica organizacional, que primava pelo rígido controle de todas suas atividades, afazeres e tarefas, pois, de acordo com a antiga ordem, “encerrada nestes locais escuros, úmidos e mal ventilados, a mulher representava o elo mais fraco da cadeia anti-higiênica visada pelos médicos” (COSTA, 1989, p. 115). A cozinha, antes um espaço pequeno, sujo e desorganizado - fora do corpo da casa -, a partir de meados do século 20 é anexada ao ambiente doméstico, no qual, devidamente ordenada e higienizada, passou a demonstrar a preocupação da dona de casa com a saúde e o bem-estar de sua prole. Neste sentido, a intenção das religiosas, com a promoção do curso de artes culinárias, era possibilitar que esposas e filhas dos operários mineiros aprendessem a cozinhar alimentos diversos, bem como recebessem instrução sobre as noções básicas para implementar uma dieta balanceada entre os membros de sua família, sempre zelando pelo asseio básico do espaço físico que comportava a cozinha e os alimentos ali preparados (ÁLBUM/Relatório, 1955-1957). A foto (Figura 1) abaixo é um retrato da época e demonstra um dia de atividades no curso de arte culinária desenvolvido pelas religiosas, no qual as mulheres aparecem realizando atividades voltadas ao espaço da cozinha. De touca e avental brancos, a fotografia sugere a preocupação com a higiene e o asseio dentro deste ambiente.

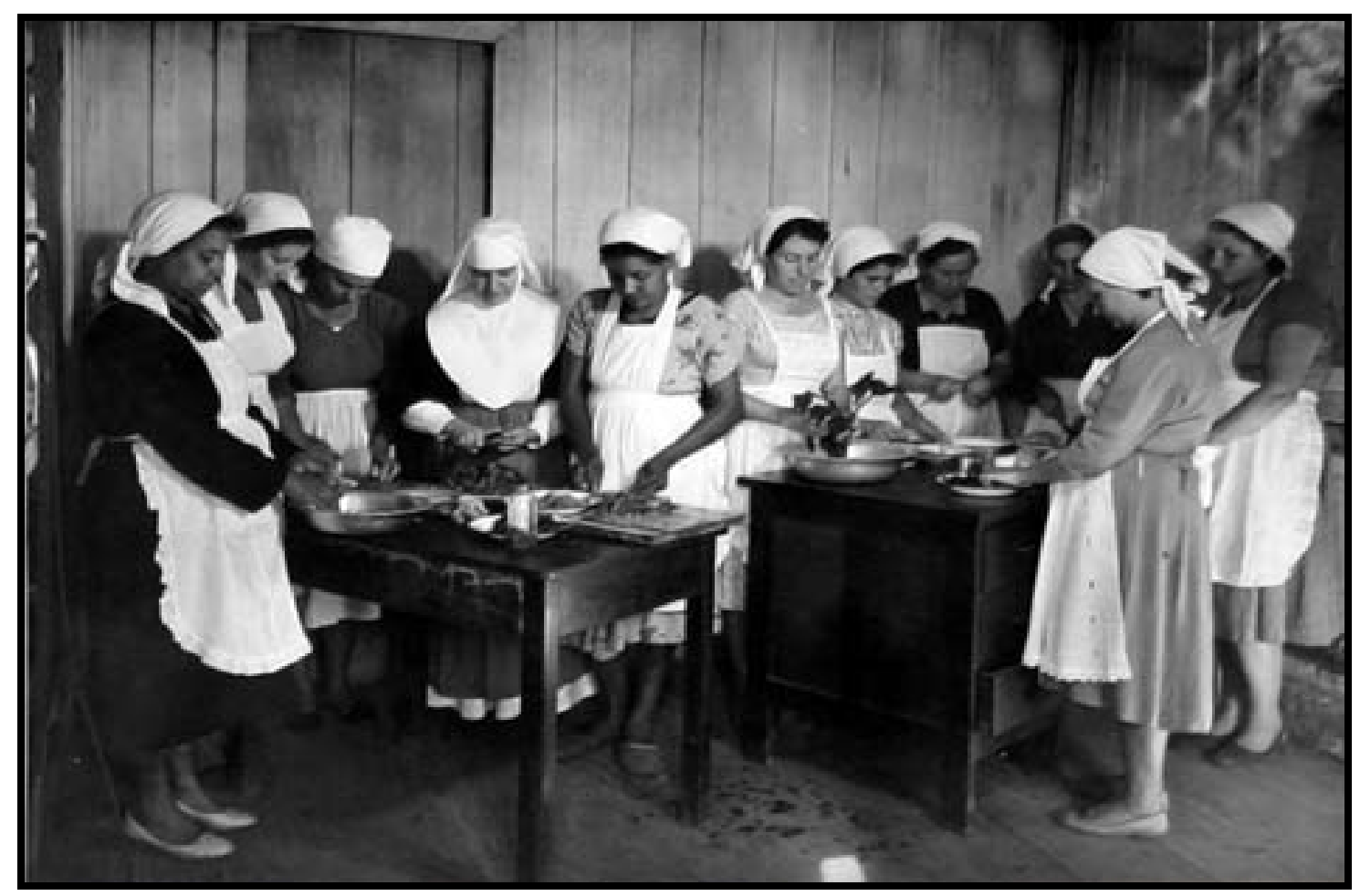


Figura 1: Curso de Arte Culinária, preparo dos alimentos - Criciúma/SC (década de 1950).

Fonte: Álbum/Relatório das atividades das pequenas Irmãs da Divina Providência. (1955-1957) - SESI Criciúma/SC.

Sabe-se que o dia-a-dia das mulheres casadas da vila operária Próspera, assim como o de tantas outras mulheres, era repleto de obrigações. Pela manhã, antes do nascer do sol, quando todos ainda estavam dormindo, ela se levantava e preparava o café dos filhos/as e do marido que logo sairia para trabalhar; depois, arejava as cobertas e recolhia as roupas sujas; em seguida, arrumava os quartos e preparava o almoço. Concomitantemente a estas tarefas, era necessário olhar as crianças. Entre o fim da lavação e antes de iniciar o jantar, sentada na soleira da porta, geralmente o lugar mais iluminado da casa, as mulheres dedicavam-se ao conserto de roupas. Com agulha e linha nas mãos, remendavam calças e meias, transformavam velhos lençóis em fronhas, puídas cortinas de chita em vestidinhos para as meninas, toalhas de mesa em panos de pratos e, com as sobras de tecidos, faziam preenchimento para travesseiros. Saber costurar permitia à mulher contribuir para o orçamento da família. Esta era uma forma legítima de ganhar dinheiro, pois, para tal trabalho, a dona-de-casa não precisaria afastar-se do lar nem comprometer seus afazeres diários. ${ }^{3}$

Segundo a lógica burguesa, que se tentou impor às camadas urbanas pobres, destinavam-se aos homens o impetuoso mundo público e a magia que o envolvia, o frenético vai-e-vem de coisas; às mulheres restava o confinamento no espaço doméstico, onde eram responsáveis pela execução ordenada e monótona de todos os afazeres cotidianos.

Cuidando da casa de acordo com os ditames da moderna ciência da economia doméstica, a dona-de-casa garantia a prosperidade da família. Controlada nos gastos e higiênica nos cuidados com a casa, deixava o espaço doméstico imune às agressões e influências externas que constantemente levavam ao desmoronamento das relações familiares (CARVALHO, 2008, p. 243). Responsável pela organização do cotidiano familiar, a mulher/mãe precisava organizar com perfeição o seu dia, procurando da melhor maneira possível dar conta de todas as atividades domésticas que lhe competiam, para que, ao final do dia, tudo estivesse pronto e ela "livre” para se dedicar exclusivamente ao marido e aos filhos. Para Maluf e Mott:

Daí a necessidade de ter método, organizar bem as atividades a se realizar no dia-a-dia, aproveitar o tempo e, mais que isso, fazer uma "administração

\footnotetext{
${ }^{3}$ Sobre o cotidiano feminino da primeira metade do século 26, ver BASSANEZI; COSTA [1989]; FONSECA; MATOS; RAGO.
} 
científica" das tarefas a se desempenhar, para que as coisas não fossem feitas no atropelo [...] (1999, p. 406).

A fim de disponibilizar as "ferramentas" para o bom andamento das atividades domésticas, as Pequenas Irmãs da Divina Providência levaram também para a vila Próspera o famoso curso de corte e costura patrocinado pelo SESI-SC, já implementado em diferentes áreas de mineração da cidade, assim como em outras regiões industriais do estado. Na referida vila operária, o curso foi rebatizado com o nome de Serviço Prático de Costura. O SESI-SC fornecia parte do material e das máquinas de costura e apontava como principal objetivo de sua atuação expandir "benefícios de caráter econômico com o aumento de capacidade de produção da família” (O SESI em Santa Catarina, 1954, p. 7). O curso, iniciado em abril de 1957, tinha o seguinte programa:

$$
\begin{aligned}
& 1 \text { - Cerzir e remendar } \\
& 2 \text { - Calça para homem } \\
& 3 \text { - Camisa para homem } \\
& 4 \text { - Roupinha de criança } \\
& 5 \text { - Vestidos } \\
& 6 \text { - Bordados }
\end{aligned}
$$

(ÁLBUM/Relatório, 1955-1957).

Ministrado pelas religiosas, o curso funcionava na casa de uma das alunas, onde, uma vez por semana, as mulheres se reuniam para aprender técnicas de costura. Saber costurar permitiria diminuir os gastos domésticos com vestuário. Na região, as mulheres compravam uma só peça de tecido (fazenda) e daí confeccionavam roupas para toda a família. Além de economizar, as roupas feitas em casa ainda eram consideradas melhores do que as industrializadas, pois duravam muito mais tempo. Abaixo (Figura 2), uma imagem das alunas do curso de corte e costura confeccionando roupas para seus filhos/as e maridos sob os cuidados de uma das religiosas. 


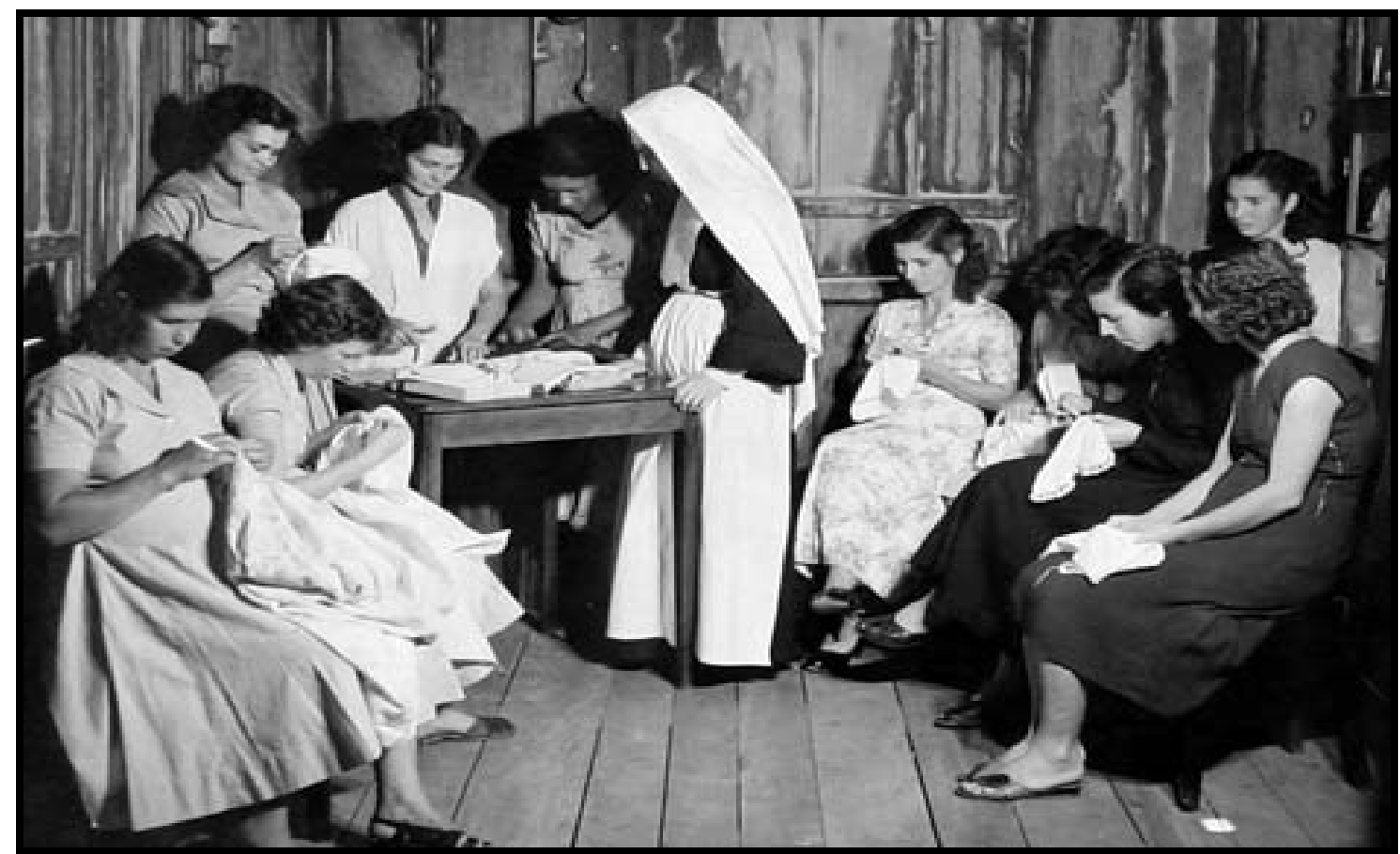

Figura 2: Serviço Prático de Costura - vila operária Próspera - Criciúma/SC (década de 1950)

Fonte: Álbum/Relatório das atividades das pequenas Irmãs da Divina Providência. (1955-1957) - SESI Criciúma/SC.

A transformação dos restos de retalhos era uma das principais atividades ensinadas pelas religiosas às mulheres da vila. Como relembra o senhor Antônio: “a D. Dulce me disse, que a Irmã ensinou a ela aproveitar todos retalhinhos que sobravam de sua costura, e com os restos ela fazia colcha de retalhos, assim ela aprendeu a fazer este tipo de artesanato, foi a Irmã quem a ensinou” (2008). A confecção de roupas masculinas, assim como de roupas infantis, também era prioridade nas aulas práticas do curso. Quando chegaram à vila operária Próspera, chamou a atenção das religiosas o fato de as crianças andarem quase sempre seminuas. De acordo com a irmã Luiza, "no começo [...] os meninos ficavam vestidos apenas com as camisetinhas, e as meninas só de calcinha” (IRMÃ LUIZA, 2007).

Cuidar da indumentária masculina passou a fazer parte das obrigações das mulheres que moravam nas áreas de mineração. Devido às características do trabalho no interior das minas e ao fato de a carbonífera não oferecer uniformes para os operários, as mulheres tornaram-se as responsáveis pela manutenção das roupas utilizadas nas frentes de exploração. Na imagem a seguir (Figura 3), vemos os resultados dos ensinamentos do curso de corte e costura; na foto, uma das alunas apresenta uma peça de roupa infantil confeccionada durante as aulas. 


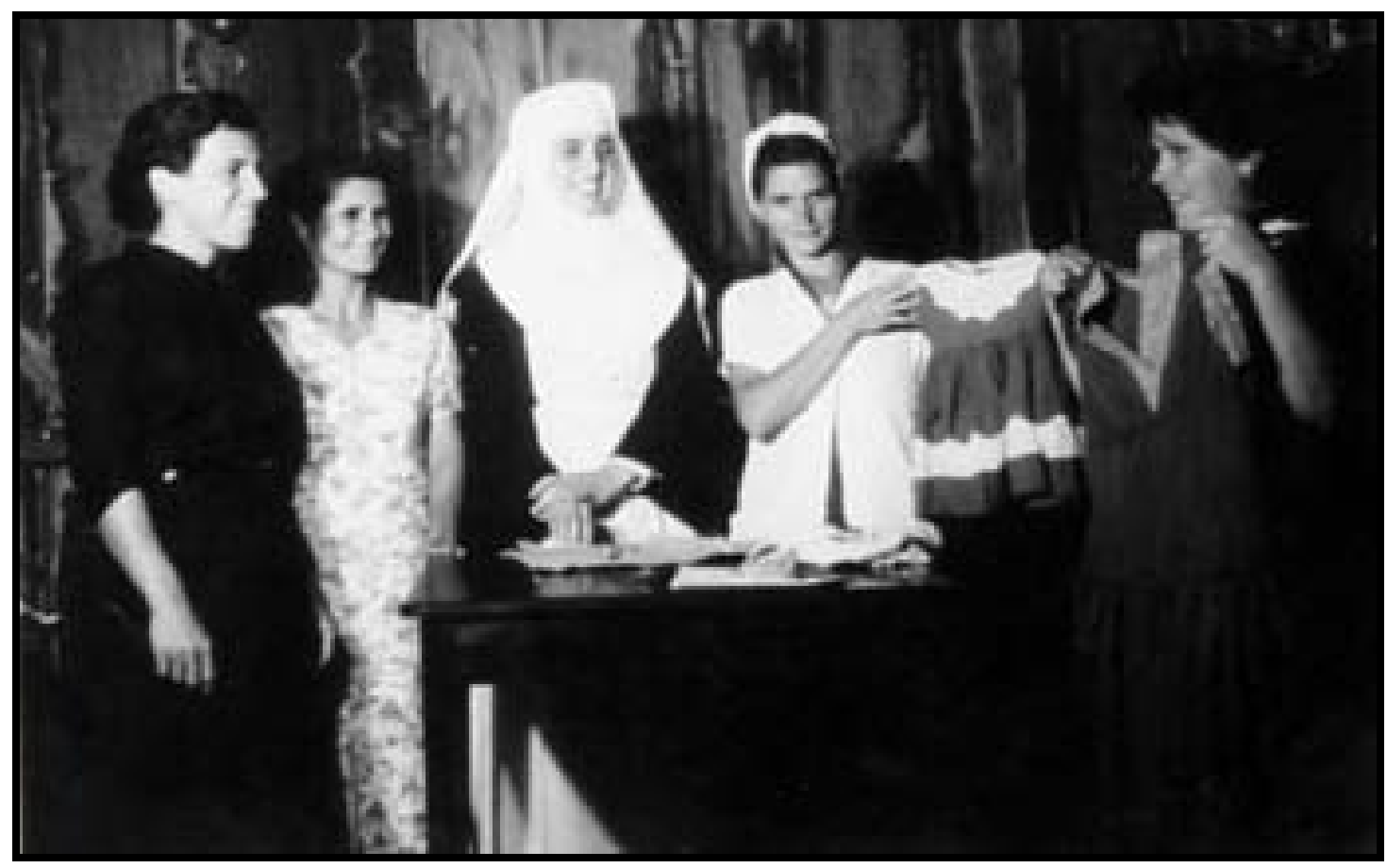

Figura 3: Resultados do Serviço Prático de Costura realizado na vila operária Próspera Criciúma/SC (década de 1950)

Fonte: Álbum/Relatório das atividades das pequenas Irmãs da Divina Providência. (1955-1957) SESI - Criciúma/SC.

Os cursos dados pelas religiosas e destinados às mulheres casadas reforçavam as identidades de gênero, atribuídas ao masculino e ao feminino, forjadas pela sociedade burguesa. Sem romper com as relações simbólicas que permeavam a vida familiar, as atividades educativas desenvolvidas em torno dos afazeres domésticos entronavam o marido como chefe da casa como responsável por seu sustento. Às mulheres casadas cabiam as atividades ligadas ao âmbito do doméstico (lavar, passar, costurar, etc.), tarefas que não desestabilizavam a perfeita ordenação da casa, perpetuando a idéia de que o lugar do feminino é o lar, inviabilizando mudanças nesse modelo familiar e nas relações de gênero (MAGALHÃES, 2005, p. 42).

Conforme apontado anteriormente, além dos trabalhos manuais realizados junto com as mulheres casadas, as religiosas também se empenharam em executar uma série de atividades junto ao Grupo das Floristas, grupo formado em abril de 1956 por jovens, filhas de mineiros, na idade entre 12 e 15 anos. De acordo com as religiosas, "a primeira atividade escolhida por elas foi a confecção de quadrinhos, cachepôs de vidro e flores artificiais. Daí o nome que mais tarde recebeu: Grupo das Floristas” (ÁLBUM/Relatório, 1955-1957). No grupo das floristas, as jovens tinham noções de bordado, costura, tapeçaria, pintura, etiqueta e civilidade. Na década de 1950, uma “moça de família”, digna de casamento, era reconhecida 
por sua moral sexual recatada e por suas habilidades no âmbito do espaço doméstico (BASSANEZI, 1996, p. 610). Aprendendo estes ofícios, que poderiam ser executados dentro da própria casa, as jovens poderiam ganhar algum dinheiro e ainda confeccionar o seu próprio enxoval, peça de grande importância para toda moça pobre que sonhava com uma vida conjugal, visto que este era o único que ela levaria por ocasião do casamento.

Durante as aulas, as irmãs, possivelmente, aconselhavam as meninas sobre os valores da castidade, do trabalho e de uma conduta moral e sexual respeitosa, alertando-as que "seria prejudicial aos seus planos de casamento ter fama de leviana” (BASSANEZI, 1996, p. 612). Além do controle sobre seus comportamentos morais, conforme os padrões de sexualidade vigente, as moças também aprendiam “as regras elementares de civilidade” (ÁLBUM/Relatório, 1955-1957), pois era imprescindível para uma futura esposa e dona de casa conhecer as elegantes regras de etiqueta, tão requisitadas pelo mundo urbano (MALUF; MOTT, 1999, p. 396-397).

A foto a seguir (Figura 4) mostra alguns destes elementos de civilidade apregoados pelas religiosas, tais como, saber pôr uma mesa e portar-se nela, o modo correto de sentar, de segurar a xícara, de colocar os braços, etc. Ao final de cada curso, as irmãs organizavam uma exposição no salão paroquial da igreja com o intuito de mostrar aos moradores da vila operária Próspera os resultados obtidos ao longo de meses de dedicação. Esta mostra de trabalhos era uma forma de premiar as participantes por seu bom comportamento, assim como instigar aquelas que por algum motivo haviam desistido a reingressarem no grupo de trabalhos manuais. Segundo a irmã Luiza:

Fizemos várias exposições de trabalhos, [...] vendíamos e dividíamos o dinheiro, elas ficavam felizes da vida com esse dinheiro, qualquer tostão era um grande valor para elas, então no curso de corte e costura, fazíamos todos os anos a exposição dos trabalhos (2007). 


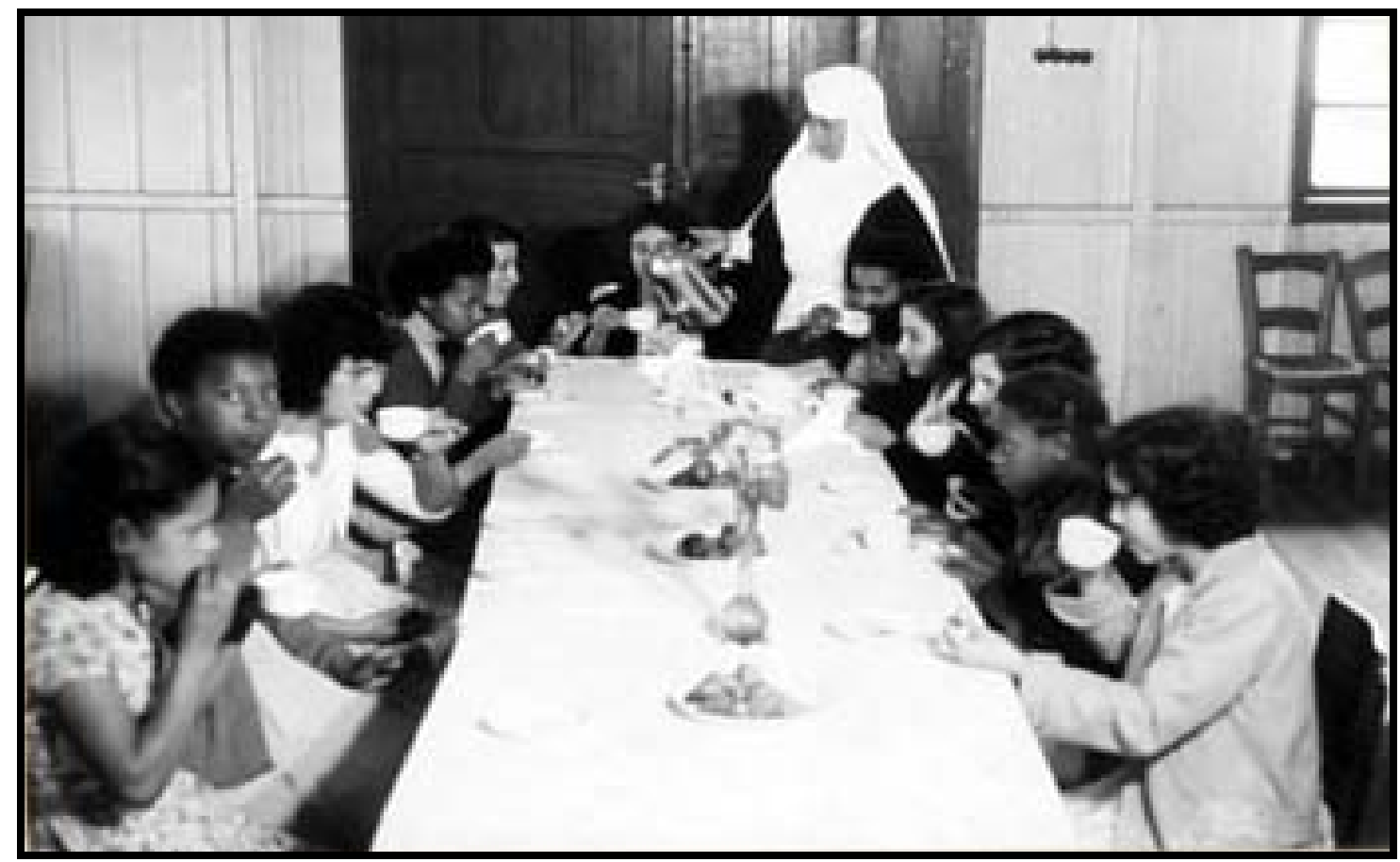

Figura 4: Dia festivo - Criciúma/SC (década de 1950)

Fonte: Álbum/Relatório das atividades das pequenas Irmãs da Divina Providência. (1955-1957) - SESI Criciúma/SC.

Outro conjunto de práticas relacionadas à saúde, implementadas pelas irmãs junto às esposas dos operários mineiros, foi o curso de Enfermagem Caseira. Desde junho de 1951, após a publicação da Carta Encíclica Evangelli Praecones, do Papa Pio XII, ficou decidido que os institutos e congregações religiosos difundiriam, em suas missões de evangelização e amparo aos pobres, os princípios da higiene através de uma intensa assistência sanitária baseada nos preceitos científicos de saúde. Para os arautos do Vaticano:

[...] é preciso que os religiosos e religiosas chamados para este frutuoso trabalho, adquiram, antes de partir, a preparação intelectual e moral hoje requeridas. Sabemos que não faltam religiosas, possuidoras de diplomas oficiais, que estudaram doenças horríveis [...] e lhes encontraram remédios apropriados. Merecem bem justos louvores. A elas, como a todos os missionários que trabalham dedicadamente [...] abençoamos nós com amor paternal, admirando caridade tão heróica (VATICANO, 1951).

Além dessas diretrizes, as religiosas tinham outros motivos para realização do curso de Enfermagem Caseira. Devido aos parcos recursos clínicos existentes na vila operária e ao fato de o único hospital da cidade sofrer de deficiência crônica de leitos e de médicos, as irmãs eram constantemente solicitadas a prestar atendimento médico à população, a qualquer hora do dia ou da noite. O Código Canônico, no seu artigo 607, e as diretrizes que regiam a Congregação das Pequenas Irmãs da Divina Providência não permitiam a saída das religiosas 
do ambiente da clausura sem autorização prévia das superioras e dos ordinários dos lugares (os bispos). Esta situação tornava-se ainda mais conflituosa no caso das freiras da vila, pois estas saídas para atender à população ocorriam geralmente no período noturno, quando era proibido qualquer tipo de atividade que não fosse ligada à contemplação a Deus (NUNES, 1985). Para coibir a iniciativa da população que sempre as procurava em horários proibitivos e, ao mesmo tempo, não mais ferir o voto de obediência, sem prejuízo do atendimento aos enfermos, as religiosas propuseram a formação de uma turma de enfermeiras (ÁLBUM/Relatório, 1955-1957).

Entendida como guardiã da família, a medicina sanitarista elaborou um conjunto de orientações que deveriam orientar as mulheres em todos os momentos de sua vida cotidiana. Instruídas e bem-educadas, estas “novas mulheres”, forjadas pela higiene médica, levariam para o interior de seus lares um conjunto de prescrições com que deveriam orientar e ordenar a vida de todos os membros da família, pois, segundo os preceitos médicos, “a obediência às leis da hygiene é o segredo da boa saúde” (COBBAN; HASSON; HEALD, s/d, p. 9). Percebido como baluarte da moral e da civilidade, coube ao feminino difundir entre os membros da sociedade os efeitos benéficos de uma vida saudável em consonância com as normas médicas.

O discurso médico propalava a necessidade de se impor uma profilaxia antimicrobiana aos lares, nos quais a principal agente seria a mulher. Cabia à mulher a responsabilidade pela saúde e pelo bem-estar de seus membros e, portanto, ampliava-se sua responsabilidade como dona-de-casa no controle dos mandamentos de higiene, principalmente em relação à infância (MATOS; MORAIS, 2007, p. 25).

Fazendo vezes de educadoras sanitárias, as freiras recebiam a formação técnica do Serviço Social da Indústria e difundiam estes conhecimentos através de cursos populares. Para Maria Lúcia Mott (2001, p. 221-222), as educadoras sanitárias cumpriram um importante papel no combate às práticas tradicionais no cuidado com as crianças, difundindo conhecimentos de higiene infantil, amamentação e dietética, organizando curso de puericultura entre a população pobre.

Para suprir em certa medida às necessidades básicas relativas à saúde, o programa do curso de Enfermagem Caseira contemplava noções de higiene, injeção intramuscular, injeção endovenosa, esterilização, curativos, tomada de temperatura, ética da enfermeira e lavagem intestinal. Para poder exercer a atividade entre os moradores, as aspirantes a enfermeira passavam por um exame final com o objetivo de avaliar os conhecimentos adquiridos ao 
longo do curso. O teste era elaborado pelo médico da companhia mineradora e somente após o crivo deste especialista é que elas seriam consideradas aptas a iniciar seus trabalhos.

Assim, apoiados nos preceitos da higiene, compartilhando a ansiedade quanto à regeneração da raça, instrumentalizados pelos conhecimentos da eugenia e imbuídos do sentimento nacionalista dominante, esses médicos atribuíram-se a tarefa de preparar as mulheres para o exercício da maternidade segundo a racionalidade científica. O discurso médico maternalista produziu, entre outras, uma dupla conseqüência. De um lado, os médicos higienistas legitimavam-se como puericultores, especialistas na promoção e manutenção da saúde das crianças, conquistando maior autoridade na sociedade e no interior do corpo médico. De outro, contribuíam para a redefinição dos papéis femininos e a configuração de um novo papel social para a mulher: a mãe moderna (FREIRE, 2008, p. 160).

Compartilhar com as mulheres os saberes da medicina, além de garantir a manutenção de uma família sadia, coibia a atuação dos famosos curandeiros e benzedeiras que há muito tempo agiam entre os moradores da região, receitando e prescrevendo beberagens e xaropadas na tentativa de curar as enfermidades. Através das visitas domiciliares, as enfermeiras ficavam a par das enfermidades que acometiam as crianças, aconselhando as mães a procurarem os serviços médicos ao invés de curandeiros ou benzedeiras. A mãe-enfermeira passou a ser a principal responsável pelo bem-estar de sua família e de seus vizinhos.

O discurso médico intervinha e racionalizava práticas que antes ficavam por conta do conhecimento tradicional das parteiras, nutrizes, aias e comadres. Por meio da intensa circulação de material, as campanhas eram realizadas por vários canais; buscava-se participar da ordenação da vida daqueles que não faziam parte dos círculos médicos. A educação sanitária, uma especificidade da saúde pública, passou a ser um importante meio de transmissão de conhecimentos médicos e de práticas de ações preventivas de saúde, dirigidas, sobretudo às mulheres (MATOS; MORAIS, 2007, p.27)

A imagem que se segue (Figura 5) apresenta a primeira turma formada no curso Enfermagem Caseira na vila operária Próspera. Cada vez mais presente na vida cotidiana da mulher/mãe, a medicina buscava ordenar práticas e valores relacionados às camadas populares. Responsável pela organização “científica” de sua casa e pelo bem-estar de sua prole, a dona-de-casa teve seu dia-a-dia higienicamente reordenado, atribuindo-se a ela cada vez mais responsabilidades, sobretudo no que diz respeito à ordenação saudável da vida infantil. 


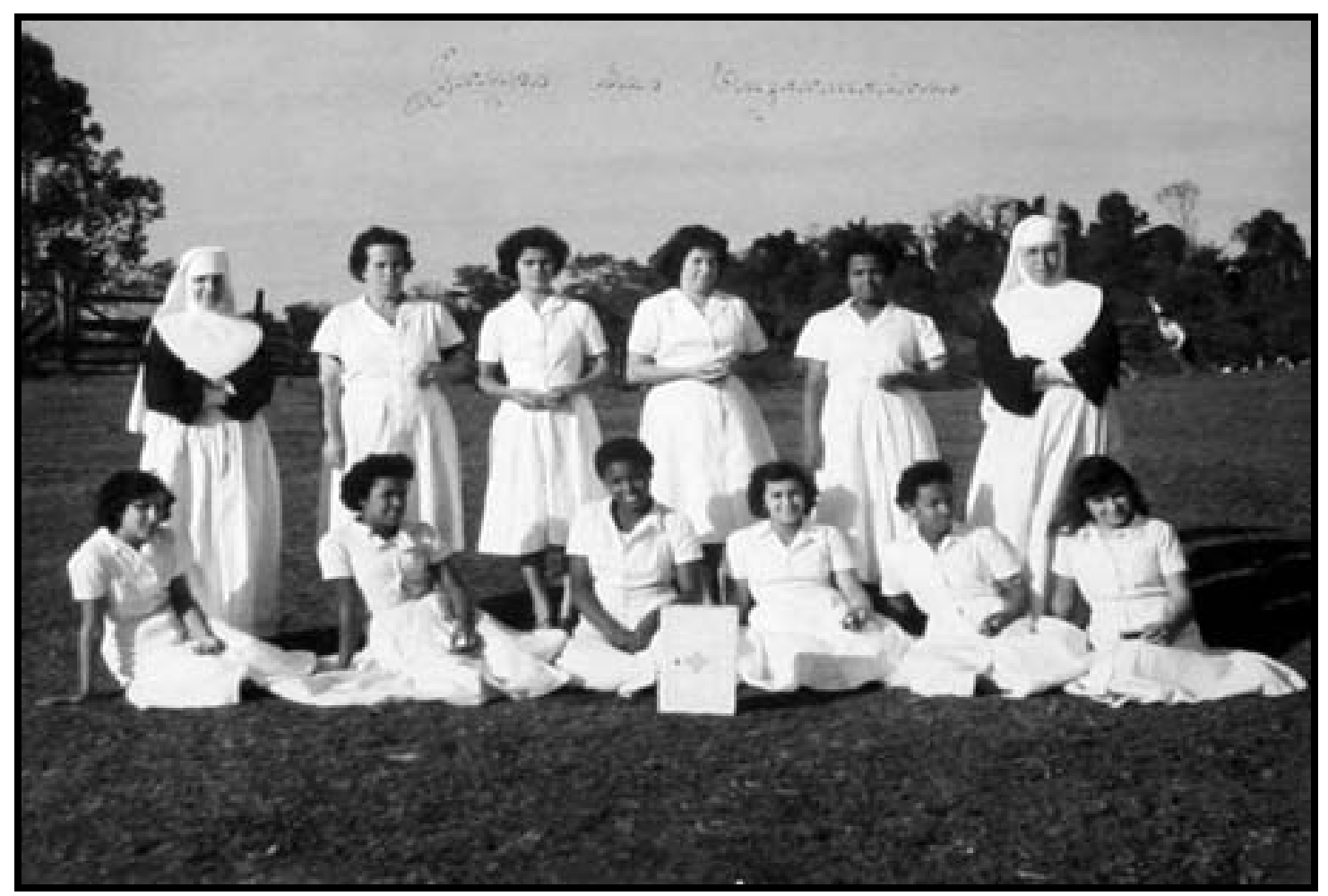

Figura 5: Primeira turma formada no curso de Enfermagem Caseira - Criciúma/SC (década de 1950) Fonte: Álbum/Relatório das atividades das pequenas Irmãs da Divina Providência. (1955-1957) - SESI Criciúma/SC.

Ao adentrar no espaço doméstico, segundo a historiadora Ana Paula Vosne Martins (2004, [b] p. 223-231), a medicina clínica preparava a mulher para sua missão como reformadora social responsável por produzir homens hígidos no corpo e no espírito, amoldados para viver em uma sociedade disciplinar. Encarcerando-as no espaço doméstico e prendendo-as em torno de funções repetitivas, a sociedade moderna criou um modelo normativo de mulher - baseada nas estruturas burguesas - que deveria ser imposto ao restante da sociedade. Dedicada e inteira no sacrifício, ela poderia realizar-se somente através dos feitos de seu marido e filhos, naturalizando o discurso de que não existiria realização feminina fora do espaço doméstico.

\section{Considerações Finais}

A ressignificação dos papéis familiares na sociedade brasileira moderna passou, necessariamente, pela naturalização dos papéis essencialmente femininos. Durante primeiras décadas do século 20, seguindo as tendências internacionais, os embates estabelecidos entre homens e mulheres no campo social foram marcados pela tentativa de tomada de direitos políticos e civis, como: regulamentação das jornadas de trabalho, direito ao voto, proteção à infância e à maternidade. Frente a estas novas conquistas femininas, forças conservadoras 
encabeçadas pelo Estado, pela burguesia e pela Igreja Católica, iniciaram uma longa campanha de reordenação da família, avivando antigas concepções naturalizadas do sexo feminino. Estas transformações da mulher e da família dependiam de um amplo projeto pedagógico que abrangia corpo e mente, pois somente a mulher saudável e instruída poderia exercer bem seu papel de mãe e também de esposa (MARTINS, 2004, [b] p. 226). A fabricação de um determinado modelo feminino tinha a intenção de apagar da memória recente um passado no qual homens e mulheres, ainda que de forma pouco difusa e por um curtíssimo espaço de tempo, vislumbraram uma sociedade baseada na equidade das relações de gênero.

Desta forma, a redefinição dos papéis familiares concentrados sobre a mulher foi a pedra fundamental no processo civilizador empreendido pelas irmãs na Vila Operária Próspera. A articulação entre as companhias mineradoras, o SESI-SC e as Pequenas Irmãs da Divina Providência, em torno dos cursos populares direcionados ao público feminino, tentou forjar um arquétipo de mulher voltado ao mundo doméstico e à família. Por meio das documentações utilizadas, principalmente os depoimentos orais e o álbum/relatório, foi possível identificar estas pretensões massificadoras na formatação de uma essência feminina, na qual cabia às mulheres o papel de dona-de-casa, disseminadora de hábitos higiênicos e civilizados; a elas não competiam as ruas e o mundo do trabalho. Esta pedagogia, baseada na promoção dos cursos populares para as mulheres, não possuía um princípio instrutivo e emancipatório do feminino; pelo contrário, tinha como finalidade substanciar a segregação sexual, relegando a mulher à esfera doméstica, sob a tutela atenta de um bondoso marido. Ao se consolidar a imagem de esferas separadas (público/privado), "a mulher foi convocada a assumir a direção do lar em nome de uma determinada definição de família” (MALUF; MOTT, 1999, p.421). Encerrada no interior do espaço doméstico, dela se esperava uma casa limpa e em ordem e que aguardasse ansiosamente pelo marido, que viria de mais um dia estafante de trabalho, sempre com a comida pronta e os olhos "brilhando de felicidade" ao revê-lo! 


\title{
MINING FAMILIES AND GENDER INEQUUALITIES: the construction of the feminine through popular courses on coal region Catarinense (1930-1960)
}

\begin{abstract}
At the peak of mining activity, the city of Criciúma attracted to the coal mines hundreds of people who moved from the South Coast of Santa Catarina, hoping to get work in the city. Without experience in the urban world or the mining industry, and regulated by time and productivity, thenew residents were blamed by the businessmen and local elite as responsible for the low productivity of the industry and for the medical/sanitary problems that affected the daily life of the citizens. In order to reverse the situation, the industry of coal Próspera Inc, SESI-SC and the religious organization Little Sisters of Divine Providence, started the process by remodeling daily living practice, of which the women were the center of the family, as wives and mothers. The model of femininity as adopted by the religious order, hegemonic in much of the westernization, was the one in which the woman would only find fulfillment and true happiness in the domestic environment. To realize this task, we designed a series of popular courses directed to the domestic space, enhancing the image of the woman as wife, housewife and family mother.
\end{abstract}

Key-Words: Gender. Family. Biopolitics.

\section{Referências}

ÁLBUM/Relatório das atividades das pequenas Irmãs da Divina Providência. (1955-1957) SESI - Criciúma/SC.

ALMEIDA, Janes Soares de. Ler as letras: por que educar meninas e mulheres? São Bernardo do Campo: UNIMEP; Campinas: Autores Associados, 2007.

ANTÔNIO Silva: Depoimento [02 de julho de 2008]. Entrevistador Ismael Gonçalves Alves. Criciúma: Acervo pessoal, 2008.

AREND, Silvia Maria Fávero. Relações de gênero e desigualdade em um Programa Social para a infância e juventude pobre (Florianópolis, Brasil década de 1930). In: Revista Otras Miradas. Vol. 7. № 1. Enero - Junio 2007. Universidad de Los Andes. p. 97-113

BASSANEZI, Carla. Mulheres dos anos dourados. In: DEL PRIORE, Mary (Org). História das mulheres no Brasil. São Paulo: Editora Contexto, 1996.

BOA NOVA JUNIOR, Francisco de Paula. Problemas médicos-sociais da indústria carbonífera sul catarinense. Boletim n ${ }^{0}$ 95. Rio de Janeiro: DNPM, 1953.

CAROLA, Carlos Renato. Dos subterrâneos da História: as trabalhadoras das minas de carvão de Santa Catarina (1937-1964). 1997. Dissertação (Mestrado em História) Universidade Federal de Santa Catarina, Florianópolis.

CARVALHO, Vânia Carneiro de. Gênero e Artefato: o sistema doméstico na perspectiva da cultura material (1870-1920). São Paulo: Editora da USP/FAPESP, 2008. 
COBBAN, F; HASSON, L. A; HEALD, G. H; O guia materno em casos de doença e emergência. Santo André: Casa Publicadora Brasileira, s/d.

COSTA, Cléria Botêlho \& MACHADO, Maria Salete Kern (Orgs.). Imaginário e História. Brasília: Paralelo 15; São Paulo: Marco Zero, 2000.

COSTA, Jurandir Freire. Ordem médica e norma familiar. Rio de Janeiro: Graal, 1989.

IRMÃ Luiza: Depoimento [05 de outubro de 2007]. Entrevistador Ismael Gonçalves Alves. Criciúma: Acervo pessoal, 2008. (Nome fictício para preservar a imagem da narradora).

FONSECA, Cláudia. Ser mulher, mãe e pobre. In: PRIORE, Mary Del. História das mulheres no Brasil. São Paulo: Contexto, 1996.

FREIRE, Maria Martha de Luna. 'Ser mãe é uma ciência': mulheres, médicos e a construção da maternidade científica na década de 1920. História, Ciências, Saúde - Manguinhos. Rio de Janeiro, v.15, supl., jun. 2008. 153-171.

LARSEN, Eirinn. Gender and welfare state. Maternalism - a new historical concept? In http://www.ub.uib.no/elpub/1996/h/506002/eirinn.html

LOWENTHAL, David. Como conhecemos o passado. Revista Projeto História. n. 17. 1998. p. 63-200.

MADEIRA, Felícia Reicher. Quem mandou nascer mulher? Estudos sobre crianças e adolescentes pobres no Brasil. Rio de Janeiro: Record/Rosa dos Tempos; 1997.

MAGALHÃES, Belmira. As marcas do corpo contando a história: um estudo sobre a violência doméstica. Maceió: EDUFAL, 2005.

MALUF, Marina; MOTT, Maria Lúcia. Recônditos do mundo feminino. In: SEVCENKO, Nicolau (Org). História da vida privada no Brasil: República: da Belle Époque à era do rádio. Volume 3. São Paulo: Companhia das letras, 1998.

MARTINS, Ana Paula Vosne. Políticas da Maternidade: Uma introdução à história comparada de gênero e políticas públicas. Relatório de estágio de pós-doutorado, 2004. [a]

Visões do feminino: a medicina da mulher nos séculos XIX e XX. Rio de Janeiro: Editora FioCruz, 2004.[b]

MATOS, Maria Izilda Santos de; MORAIS, Mirtes. Imagens e ações: gênero e família nas campanhas médicas (São Paulo: 1890-1940). In: ArtCultura. Uberlândia, v. 9, n. 14, jan.jun. 2007. p. 23-37.

MOTT, Maria Lúcia. Maternalismo, políticas públicas e benemerência no Brasil (1930-1945) In: Cadernos Pagu. n 16, 2001.

NUNES, Maria José F. Rosado. Vida religiosa nos meios populares. Petrópolis: Editora Vozes, 1985. 
O SESI em Santa Catarina. In: Revista Paulista de Indústria. Separata ${ }^{0}$ 26, setembro de 1954.

POLLAK, Michel. Memória, esquecimento, silêncio. Revista de Estudos Históricos. Vol 2, $\mathrm{n}^{\mathrm{o}}$ 1. Rio de Janeiro, 1989. p. 03-15.

RABELO, Giani. Entre o hábito e o carvão: pedagogias missionárias no sul de Santa Catarina na segunda metade do século XX. 2007.Tese (Doutorado em Educação). Universidade do Rio Grande do Sul, Porto Alegre.

RAGO, Margareth. Do Cabaré ao Lar: a utopia da cidade disciplinar, Brasil 1890-1930. 3. edição. Rio de Janeiro: Paz e Terra, 1985.

SEGALEN, Martine. A revolução industrial: do proletário ao burguês. In: (Orgs.) BURGUIÈRE, André et al. História da família: o ocidente: industrialização e urbanização. Volume 4. Lisboa: Terramar, 1999.

SILVA, João Luís Máximo da. Cozinha Modelo: O impacto do gás e da eletricidade na casa paulistana (1870-1930). São Paulo: Editora da USP, 2008.

VATICANO. Carta Encíclica Evangelii Praecones, 2 de junho de 1951.

XAVIER, Elódia. O declínio do patriarcado: a família no imaginário feminino. Rio de Janeiro: Record/Rosa dos Tempos, 1998. 